\title{
The contralateral upper eyelid in ptosis: some observations pertinent to ptosis corrective surgery
}

\author{
H. K. MEHTA \\ From the Eye and Cottage Hospital, Caernarvon, Gwynedd, Wales
}

SUMmARY The validity of Hering's law in corrective surgery for ptosis is demonstrated for the first time. It is also shown how Hering's law has been utilised in corrective surgery for unilateral ptosis to elicit a predominant response from the unoperated contralateral upper eyelid. Other implications of reciprocal innervation of the 2 upper eyelids are discussed and a tentative hypothesis is postulated that in a case of true unilateral levator ptosis the fellow upper eyelid will show compensatory retraction.

Compensatory retraction of the contralateral upper eyelid is a relatively common occurrence in patients with unilateral ptosis of an upper eyelid. But the phenomenon has received scant attention in ophthalmic literature. Evidence is presented here to show that as well as occurring frequently in ptosis this phenomenon also occurs in mechanical ptosis, and that it has the following clinical implications.

Firstly, in some patients this compensatory retraction of the fellow upper eyelid constitutes as much a cosmetic blemish as does the ptosis in the primarily affected eye.

Secondly, just as surgical operation on the extraocular muscles of one eye has effects on the actions of the corresponding muscles of the fellow eye (a phenomenon repeatedly exploited in the surgical management of patients with strabismus), so does a similar phenomenon operate in corrective surgery for ptosis. It can be utilised to 'balance' the position of the 2 upper eyelids, as follows: (a) The improvement of unilateral ptosis by levator resection is frequently accompanied by reduction in the compensatory retraction of the unoperated fellow upper eyelid. (b) In some patients in whom gross surgical overcorrection of unilateral ptosis has caused unsightly ipsilateral upper eyelid retraction the unoperated contralateral upper eyelid develops a compensatory ptosis. When the overcorrection is relieved by levator recession surgery, the compensatory ptosis of the contralateral upper eyelid is also relieved.

Thirdly, in cases of bilateral ptosis, when uni-

Address for reprints: H. K. Mehta, FRCS, Derwen Deg, Bangor, Gwynedd, Wales. lateral surgical correction is carried out the improvement of the ptosis of the operated eyelid may accompany worsening of the ptosis of the untreated upper eyelid.

To my knowledge this is the first report of clinical utilisation of this synkinetic oculopalpebral phenomenon in ptosis corrective surgery.

\section{Case reports}

These have been classified into 4 categories. Group I: Unilateral ptosis with mild to moderate compensatory retraction of the contralateral upper eyelid (Case 1). Group II: Unilateral ptosis with gross compensatory retraction of the contralateral upper eyelid (Cases 2 and 3). Group III: Bilateral ptosis (Cases 4 and 5). Group IV: Unilateral mechanical ptosis with compensatory retraction of the contralateral upper eyelid (Cases 6 and 7).

\section{CASE 1}

A woman aged 74 with senile ptosis of the left upper eyelid and a mild compensatory retraction of the right upper eyelid (Fig 1a). Ptosis correction of the left upper eyelid was carried out by a $10-\mathrm{mm}$ levator resection and a $2-\mathrm{mm}$ tarsectomy. The result 8 weeks later shows a satisfactory correction of the ptosis and diminution of the retraction of the unoperated right upper eyelid (Fig. 1b).

\section{CASE 2}

A girl aged 13 with congenital ptosis of the left upper eyelid and total inaction of the ipsilateral superior rectus also had gross compensatory retraction of the right upper eyelid (Fig. 2a). The parents 


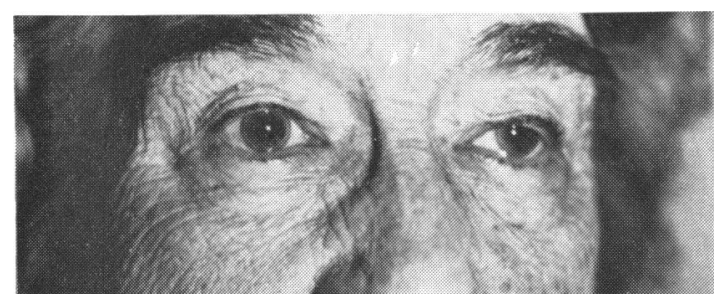

Fig. 1 (a) Preoperative appearance of senile myogenic ptosis of left upper eyelid and mild compensatory retraction of the right upper eyelid

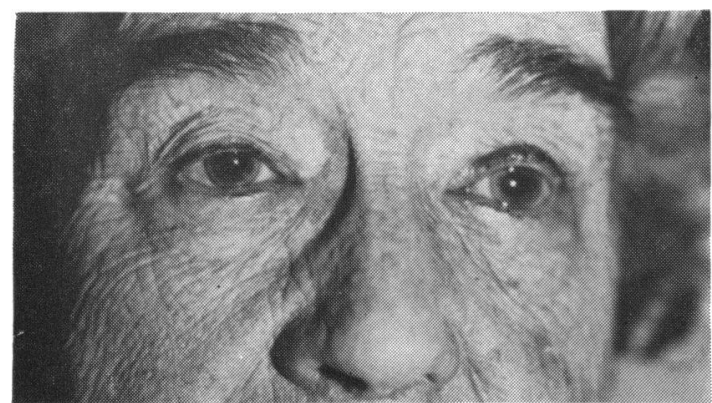

Fig. 1 (b) Postoperative appearance 2 months after a left levator resesection of $10 \mathrm{~mm}$, and $2 \mathrm{~mm}$ tarsectomy performed under local anaesthesia as a day case: satisfactory correction of the ptosis and diminution of the retraction of the unoperated right upper eyelid

and the child were as much concerned about the staring right eye as they were about the ptosis. As there was total absence of Bell's phenomenon, and as the left eye used to remain half open during sleep, when discussing surgical correction it was explained to the parents that full correction of the ptosis might usher in exposure keratopathy, and that a small levator resection of the left upper eyelid would probably not only produce some improvement in the ptosis but also that the right upper eyelid would probably respond by lessening its retraction. The result of a deliberately small levator resection $(10 \mathrm{~mm})$ of the left upper eyelid is shown in Fig. $2 b$.

The improved appearance in this case has been achieved by 3 factors-minimal improvement in the ptosis, formation of a lid fold, and a reduction in the retraction of the right upper eyelid.

CASE 3

A man aged 82 when seen in February 1976 had ptosis of the left upper eyelid due to a total left 3rd nerve palsy. He also had gross compensatory retraction of the right upper eyelid (Fig. 3a). Six months later, there being no improvement in the 3rd nerve palsy, a 14-mm resection of left levator with 2-mm tarsectomy was carried out. The primary aim was to reduce the compensatory retraction of the right upper eyelid, as it was accepted that the paralytic ptosis was unlikely to improve even after the ipsilateral levator resection. The result 3 months after surgery (Fig. $3 b$ ) shows the expected reduction of the retraction of the right upper eyelid.

\section{CASE 4}

A woman aged 54 with severe bilateral acquired ptosis of undetermined aetiology wanted surgical correction because the drooping eyelids severely obstructed her vision (Fig. 4a). One week after a left levator resection of $14 \mathrm{~mm}$ and $2 \mathrm{~mm}$ tarsectomy there was an improvement of ipsilateral ptosis, but worsening of the ptosis of the right upper eyelid (Fig. 4b). The final satisfactory result after right levator resection is seen in Fig. $4 c$.

The worsening of the ptosis of the unoperated

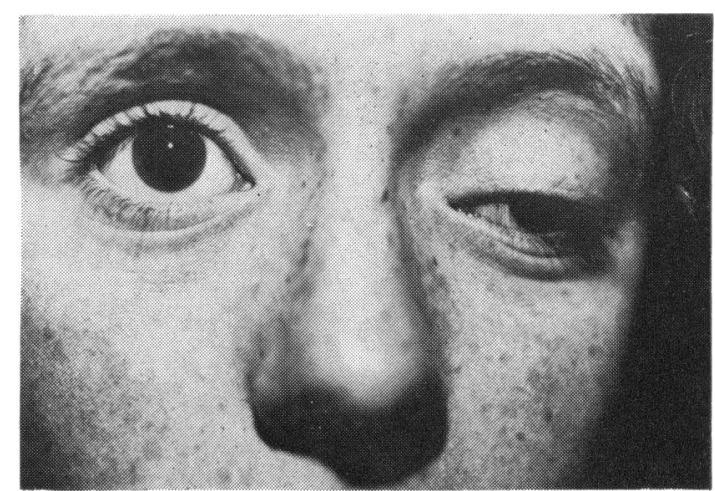

Fig. 2 (a) Preoperative appearance of congenital ptosis of the left upper eyelid and gross compensatory retraction of the right eyelid in a child aged 13

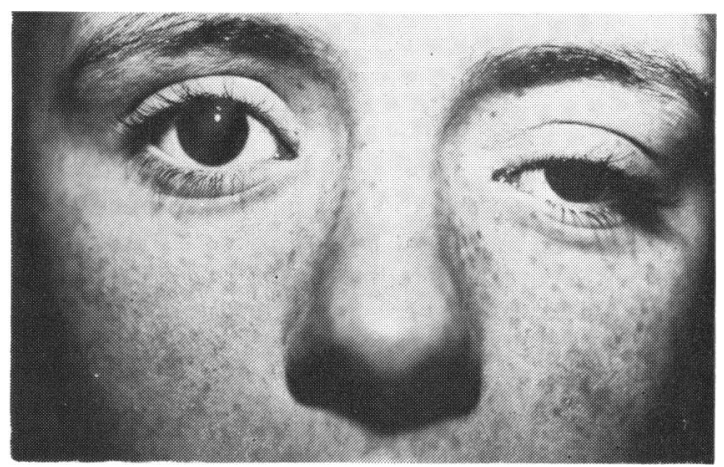

Fig. 2 (b) Postoperative appearance after a deliberately small resection of $10 \mathrm{~mm}$ of the left levator shows reduction of ptosis and formation of a lid fold on the left upper eyelid, and the anticipated reduction of retraction of the right upper eyelid 


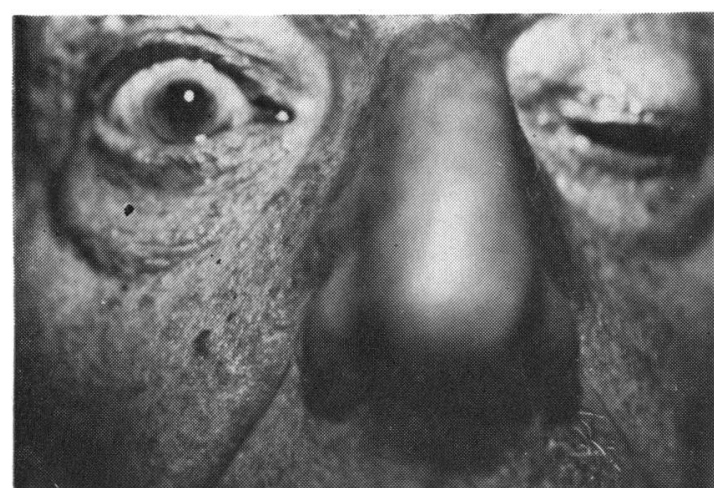

Fig. 3 (a) Preoperative appearance of paralytic ptosis of the left upper eyelid due to a total left 3rd nerve palsy of 6 months' duration. Note the gross compensatory retraction of the right upper eyelid

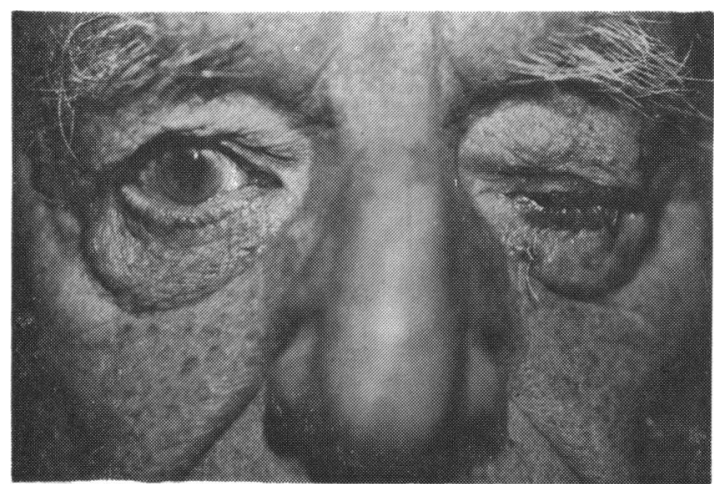

Fig. 3 (b) Postoperative appearance after $14 \mathrm{~mm}$ resection of levator and $2 \mathrm{~mm}$ tarsectomy on the left side with a primary view to eliciting reduction of retraction of the right upper eyelid

upper eyelid after contralateral levator resection is noteworthy.

CASE 5

A 76-year-old man with senile myogenic ptosis of the left upper eyelid did not have a compensatory retraction of the right eyelid (Fig. 5a). Phenylephrine $10 \%$ drops were instilled in the left eye only. Ten minutes later there was improvement in the ptosis of the left eye and reciprocal drooping of the upper eyelid of the right eye (Fig. $5 b$ ).

The absence of compensatory retraction of the right upper eyelid suggests that possibly this may eventually turn out to be a case of bilateral ptosis.

CASE 6

A 60-year-old man was operated on for repair of a laceration of the left upper eyelid which also in- volved the lateral half of the levator palpebrae. Fig. 6 shows the appearance 2 weeks after the repair. Note the mechanical ptosis of the left upper eyelid and retraction of the right upper eyelid.

CASE 7

A man aged 73 with herpetic keratitis developed 'mechanical ptosis' of the right upper eyelid and

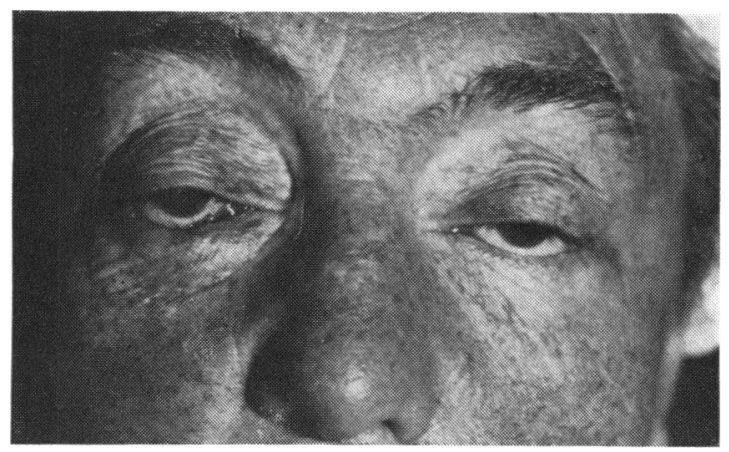

Fig. 4 (a) Severe bilateral acquired ptosis of unknown aetiology in a woman aged 54-preoperative

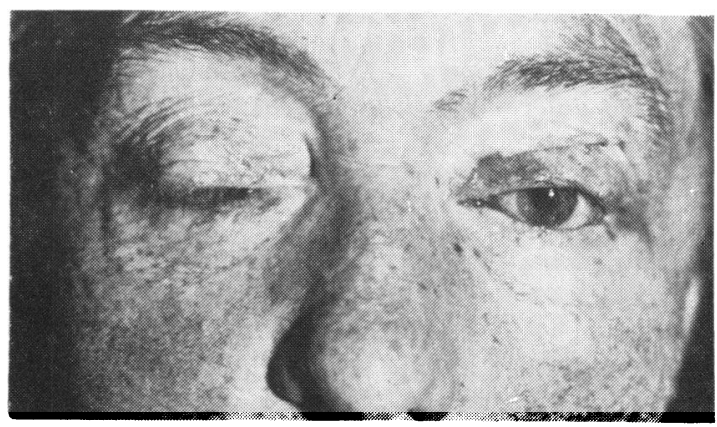

Fig. 4 (b) Improvement of left ptosis 1 week after a left levator resection of $14 \mathrm{~mm}$ and $2 \mathrm{~mm}$ tarsectomy. Note the worsening of ptosis of the right upper eyelid

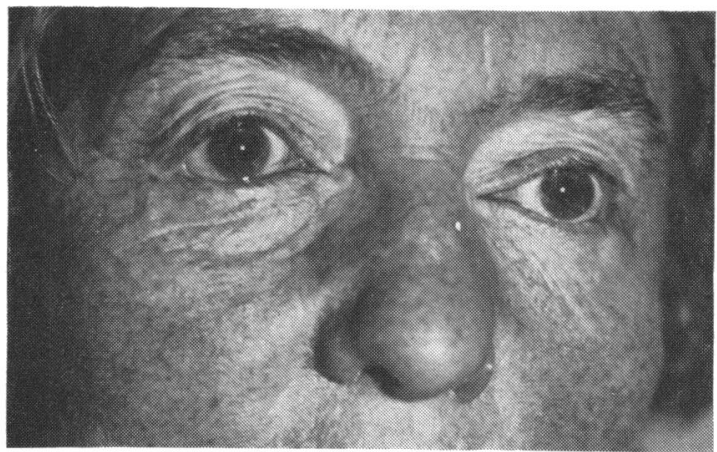

Fig. 4 (c) Final satisfactory appearance after right levator resection 
compensatory retraction of the left upper eyelid (Fig. 7).

\section{Discussion}

Compensatory retraction of the contralateral upper eyelid in cases of unilateral ptosis was first reported by Walsh (1957) and subsequently by Lewallen (1958), Jain (1963), Gupta et al. (1964), and Gay et al. (1967). They all explained the reciprocity of the levators of the 2 upper eyelids on the basis of a reflex mechanism obeying Hering's law. Kennard and Smyth (1963) demonstrated the presence of stretch receptors in the levator muscles. However, so far there have been no reports of clinical utilisation of Hering's law in corrective surgery for ptosis. Other authors (Table 1), with the exception of Beard (1976), who have reported the results of surgical correction of unilateral ptosis appear to have ignored (by letting pass unremarked) the

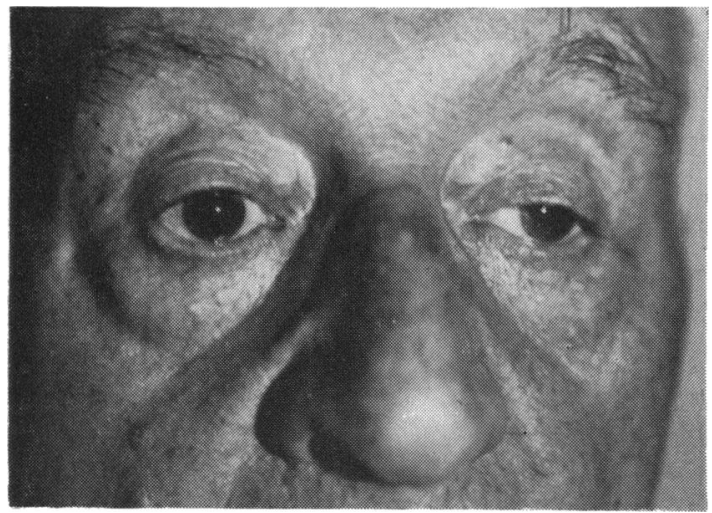

Fig. 5 (a) Senile myogenic ptosis of left upper eyelid without compensatory retraction of the right upper eyelid

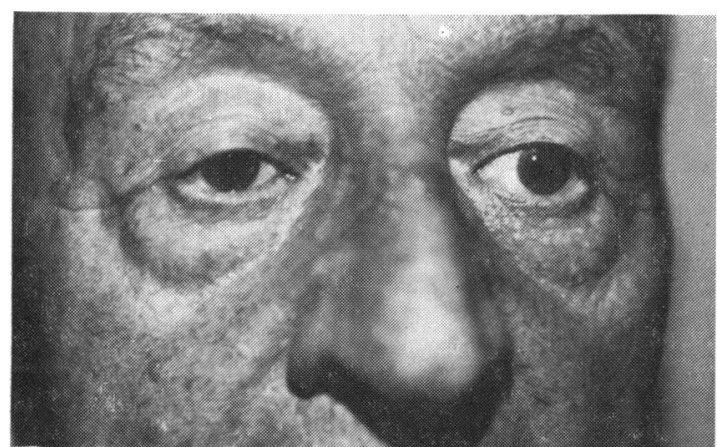

Fig. 5 (b) Appearance 10 minutes after instillation of $10 \%$ phenylephrine drops in the left eye only. Note improvement of left ptosis and reciprocal drooping of the right upper eyelid

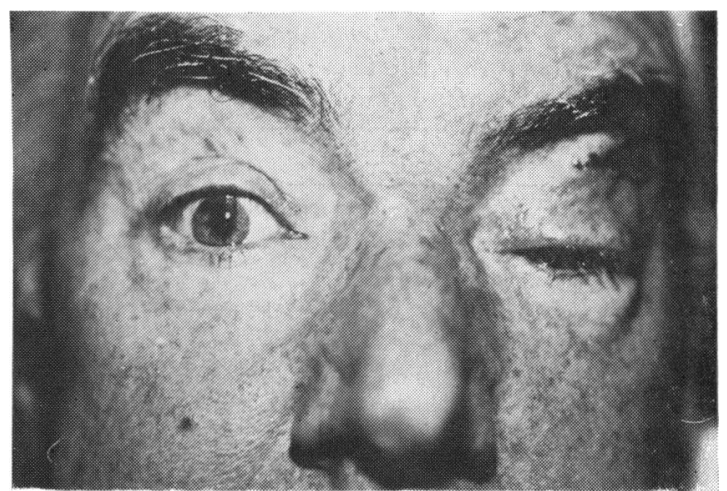

Fig. 6 Mechanical ptosis of left upper eyelid 2 weeks after repair of a laceration involving the levator. Note the compensatory retraction of the right upper eyelid

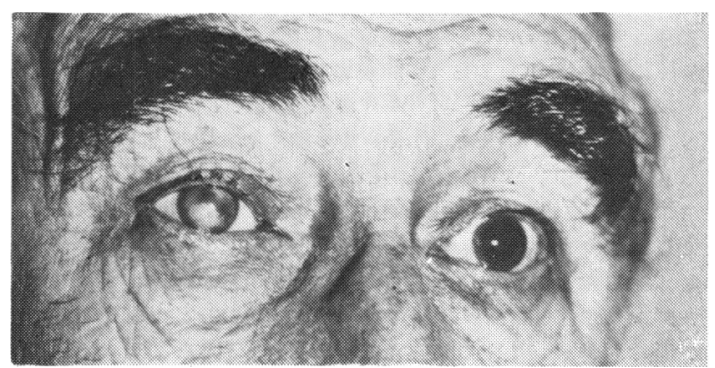

Fig. 7 'Mechanical' ptosis of right upper eyelid associated with recurrent herpes simplex keratopathy.

There is compensatory retraction of the left upper eyelid

compensatory posture alteration of the unoperated contralateral upper eyelid despite the fact that in some instances this compensatory response has contributed much to improve the patient's appearance. Similarly, some authors (Mustardé, 1968; Mustardé et al., 1970) studying the effects of instillation of cocaine-adrenaline or guanethidine drops unilaterally into the eye having ptosis have restricted their observations only to the eye under study. However, the photographs in their communication clearly indicate posture alteration of the fellow upper eyelid.

It can be seen from my Cases 2 and 3 of ptosis of poor prognosis that I have utilised Hering's law predominantly to elicit a response from the unoperated contralateral upper eyelid. In my series of unilateral ptosis with contralateral upper eyelid retraction I have opted to perform resection of the levator of the eyelid showing ptosis. But if the validity of Hering's law is to be established for the corrective surgery of ptosis, then, theoretically at least, similar results should be expected to be obtained whether one resected the levator of the 
Table 1 References from significant contributions to the literature on ptosis wherein improvement of unilateral ptosis after corrective surgery is reported without any remark about the obvious improved cosmesis brought about also by the reciprocal alteration in the postion of the unoperated fellow upper eylid

\begin{tabular}{|c|c|c|c|}
\hline Author & Source & Page numbers & Figure numbers \\
\hline Beard, C. (1969) & Ptosis, 1st edn. Mosby: St. Louis & $\begin{array}{l}93,94,98,101,103 \\
216,217,221\end{array}$ & $\begin{array}{l}7: 16 ; 7: 18 ; 7: 23 ; 7: 27 ; 7: 28 \\
13: 8 ; 13: 9 ; 13: 13\end{array}$ \\
\hline Callahan, A. (1966) & $\begin{array}{l}\text { Reconstructive Surgery of the Eyelids and Ocular } \\
\text { Adnexa. 1st edn. Aesculapius: Birmingham, } \\
\text { Alabama }\end{array}$ & $72 ; 98$ & $72-73 ; 96-97$ \\
\hline Fox, S. (1976) & $\begin{array}{l}\text { Ophthalmic Plastic Surgery. 5th edn. Grune \& } \\
\text { Stratton: New York }\end{array}$ & $374 ; 411$ & $16-7(\mathrm{I}-\mathrm{J}) ; 16-17(\mathrm{~A}$ and $\mathrm{B})$ \\
\hline $\begin{array}{l}\text { Mustardé, J. C., Jones, } \\
\text { L. T., and Callahan, A. } \\
(1970)\end{array}$ & $\begin{array}{l}\text { Ophthalmic Plastic Surgery Up-to-Date. } \\
\text { Aesculapius: Birmingham, Alabama }\end{array}$ & $54,55,58,59$ & $63 \mathrm{~A}, \mathrm{C} ; 64 \mathrm{~A}, \mathrm{~B} ; 68 \mathrm{~A}, \mathrm{~B} ; 69 \mathrm{~A}, \mathrm{~B}$ \\
\hline Rycroft, B. W. (1957) & $\begin{array}{l}\text { Transactions of the Ophthalmological Society of } \\
\text { the United Kingdom, 77, 501-511 }\end{array}$ & 507 & 158 \\
\hline
\end{tabular}

ptosed eyelid or recessed the levator of the retracted eyelid. Evidence for the efficacy of the latter can be judged by the case of Maris reported by Reeh $e t$ al. (1976). This patient, like my Case 1, showed unilateral ptosis with retraction of the fellow upper eyelid. Maris considered the 'hyperelevation' to be the primary congenital defect in his case and therefore carried out recession of the ipsilateral levator. The postoperative photograph clearly shows compensatory elevation of the contralateral eyelid, which had ptosis. It therefore looks certain that Hering's law can be used effectively to balance 2 asymmetrically positioned upper eyelids. An obvious and logical corollary of this is in cases of bilateral ptosis, when unilateral corrective surgery for ptosis is carried out. The improvement of ipsilateral ptosis may be accompanied by worsening of the ptosis of the fellow upper eyelid. The patient can be warned about this.

An analysis of my own 20 cases of unilateral ptosis of varied aetiology has shown the presence of compensatory retraction in 19 . (The only patient not showing compensatory retraction was Case 5 of this communication.) This leads me to postulate a tentative hypothesis that, if in a case of apparently unilateral levator ptosis there is absence of retraction of the fellow upper eyelid, one is probably not dealing with a true unilateral ptosis but with a potentially bilateral ptosis.

\section{References}

Beard, C. (1976). Ptosis, 2nd edn, p. 103. C. V. Mosby: St. Louis.

Gay, A. J., Salmon, M. L., and Windsor, C. E. (1967). Hering's law, the levators, and their relationship in disease states. Archives of Ophthalmology, 77, 157-160.

Gupta, J. S., Jain, I. S., and Kumar, K. (1964). Lid retraction secondary to contralateral ptosis. British Journal of Ophthalmology, 48, 626-627.

Jain, I. S. (1963). Lid retraction in the non-paretic eye in acquired ophthalmoplegia. British Journal of Ophthalmology, 47, 757-759.

Kennard, D. W., and Smyth, G. L. (1963). Reflex regulation of the upper eyelids, with observation on the onset of sleep. Journal of Physiology, 166, 168-177.

Lewallen, W. M. (1958). Lid retraction syndrome due to 'secondary deviation'. American Journal of Ophthalmology, 45, 565-567.

Mustardé, J. C. (1968). Experience in ptosis correction. Transactions of the American Academy of Ophthalmology and Otolaryngology, 72, 173-184.

Mustardé, J. C., Jones, L. T., and Callahan, A. (1970). Ophthalmic Plastic Surgery Up-to-Date, 1st edn., pp. 37, 45. Aesculapius: Birmingham, Alabama.

Reeh, M. J., Beyer, C. K., and Shannon, G. M. (1976). Practical Ophthalmic Plastic and Reconstructive Surgery, 1st edn., p. 78 (Fig. 7-4). Lea \& Febiger: Philadelphia.

Walsh, F. B. (1957). Clinical Neuro-Ophthalmology, 2nd edn., pp. 196, 778. Williams \& Wilkin: Baltimore. 